\title{
Statistics SIG: identifying and addressing issues within statistics support
}

Ellen Marshall, Department of Engineering and Mathematics, Sheffield Hallam University, Sheffield, UK. Email: ellen.marshall@shu.ac.uk

Alun Owen, School of Computing, Electronics and Mathematics, Coventry University, Coventry, UK. Email: aa5845@coventry.ac.uk

\begin{abstract}
The Special Interest Group (SIG) in Statistics Support maintained by the sigma Network for excellence in mathematics and statistics support held a discussion workshop at the CETL-MSOR conference 2018. This was focused on identifying and addressing issues within statistics support and facilitated a very interesting and valuable sharing of experiences and suggestions for good practice in the provision of statistics support. Discussions were primarily focused on the limitations and scope of statistics support, and in particular the following issues were discussed: supporting student with statistics software, understanding the remit of statistics support, supporting students with choosing statistical techniques, as well as a short discussion on raising awareness of statistics support and evidencing its impact. One key action arising from the workshop was the proposal to run a workshop on statistics software.
\end{abstract}

Keywords: Statistics, support issues, scope, remit.

\section{Overview}

The sigma Network for excellence in mathematics and statistics support (http://www.sigmanetwork.ac.uk) maintains a Special Interest Group (SIG) in Statistics Support. This SIG is focused on statistics support provided in Higher Education institutions primarily in the UK, but does have a wider global perspective since the same issues and challenges are faced worldwide. The SIG held a discussion based workshop at the CETL-MSOR conference 2018, which was focused on identifying and addressing issues within statistics support. This workshop report outlines the issues that were discussed during the workshop, as well as offering some thoughts on suggested good practice. The report is organised by reporting on the preparation and management of the workshop in Section 2, whilst Section 3 provides a commentary of the discussions at the workshop, which are then summarised in Section 4 to complete the report.

\section{Workshop preparation and management}

Prior to the workshop taking place at the conference, colleagues subscribing to the sigma-Network mailing list at (https://www.jiscmail.ac.uk/cgi-bin/webadmin?A0=SIGMA-NETWORK) were contacted, asking (irrespective of whether or not they were planning to attend the conference) to share questions they had or challenges they faced when providing statistics support. Sharing was done by posting on the workshop's padlet wall (https://padlet.com) at https://engb.padlet.com/owen a3/nob4xbxkekgi. Colleagues were invited to consider any questions or challenges posted by others, and "like" them if they shared similar questions or challenges. This was to gauge how common particular questions or challenges are. Finally, colleagues were invited to add ideas or suggestions in response to existing questions or challenges posted by others.

It was clear from the questions and challenges posted on the padlet wall prior to the conference, and the subsequent discussion of these at the workshop, that many of these related to the theme of "Limitations and Scope of Statistics Support". Figure 1 shows a slide which summarises some of the 
questions and challenges posted prior to the conference that were included in this theme. This slide was displayed at the workshop and these questions and challenges related to this theme were discussed, along with other aspects related to this theme.

\section{Limitations and Scope of Statistics Support?}

A common issue is having to tell a student that their data isn't suitable for the analysis they are trying to do. Then working out what to advise them they CAN do with their data instead.

I often come across students with limited stats training who need some quick guide on many different statistical tests... [are there resources I can refer them to?]
Often find that student has been told to do something by supervisor which is not suitable or not realistic in the time available...l generally suggest something more suitable and simpler but wonder how the student fares with the supervisor afterwards.

I have seen students who wanted to use SPSS, STATA, R, and Eviews to carry out similar (panel regression / random-fixed effects models) analysis. Do all centres support all software packages or limit to one or two?
I have found that while many statistics modules cover topics such as data visualization and testing of assumptions, they do not 'join up the dots' in a form of data analysis workflow. It would be helpful if data analysis workflow and analysis of mini-projects was included within statistics modules.
Can students who do not know what their hypotheses are be supported in any way beyond directing them back to their supervisor?

Figure 1: Questions and challenges posted prior to the conference that were included in the theme of "Limitations and Scope of Statistics Support".

A total of 10 colleagues attended the workshop who were organised into two groups, and were tasked with discussing any questions and challenges not only posted prior to the workshop, but also those that they themselves wished to discuss. The notes recorded by these two groups were captured on flipchart paper and reproduced in the appendix to this report.

The remainder of this report summarises the discussions that subsequently took place during the workshop. All of the views and opinions and recommendations expressed in this workshop report are therefore of those that attended the workshop or colleagues who contributed to the discussions prior to the workshop.

\section{Discussion}

\subsection{Support with statistics software}

A range of different statistics software is used within Higher Education (HE) institutions in the UK, but the main question shared at this workshop was "Should statistics support tutors be expected to offer support in all of them?". The most commonly used statistics software taught within H.E. institutions is still SPSS, although $\mathrm{R}$ is becoming increasingly popular. The workshop concluded that providing support with SPSS and R together with Excel could typically be expected in mathematics and statistics support centres in HE institutions. Statistics software other than SPSS or R, such as SAS, Minitab, STATA and eviews, is used in many HE institutions, and it was generally felt that, whilst statistics support tutors should be able to help with the interpretation of output from any statistics software or package, it should not be expected that tutors are proficient users of all of these. 
The main suggestion for good practice in relation to this issue related to the need to manage the expectations of students, clearly stating the statistics software that support staff were proficient in on relevant support centre websites. In addition it was also agreed that maintaining suitable links on support centre websites to resources on how to use other statistics software would be very helpful to students.

The need for tutor training with the use of statistics software was considered and it was thought that basic training in $\mathrm{R}$ would be most beneficial, as many tutors are not familiar with $\mathrm{R}$ but its popularity is increasing. There are some $\mathrm{R}$ resources available via the community resources contributed to statstutor (https://statstutor.ac.uk), whilst additional resources are available through the Sheffield Hallam Maths and Stats support centre website at https://maths.shu.ac.uk/mathshelp/Resources/. However, a basic training giving an introduction to $R$ was felt would be the easiest way for tutors to get to grips with the basics. Another software package, Nvivo (https://www.qsrinternational.com/nvivo/home), which is aimed at the analysis of qualitative and mixed methods data, was also identified as something statistics tutors would like to have training in. One outcome from these discussions was the proposal for a potential meeting of the SIG hosted at Liverpool John Moores University, focused on a training workshop on statistics software to include $\mathrm{R}$ and Nvivo and other relevant statistical software products.

\subsection{What is in the remit of statistics support?}

The provision of help and advice with statistical software is commonplace with the context of statistics support. However, it was agreed that in many cases, the software students are being expected to use is not always covered within departments' core course delivery. It was agreed that the basics of any software students are expected to use should be provided within the student's course, and that it shouldn't be an expectation that a mathematics and statistics support centre will offer the teaching and learning opportunities in this area. This is particularly true where packages that many statistics support tutors are much less likely to be familiar with, such as STATA and eviews. Indeed, it was agreed that the helping students with the basics in the use software could be seen as computing support, rather than statistics support. If the student has been told to use a specific package but has received no teaching or learning opportunities with the software, it could be argued that statistics support tutor should help the student develop skills with a package the tutor is familiar with.

One area of statistics support that it was agreed should not necessarily fall within the scope of statistics support is advising on the formulation of hypotheses or research questions in the context of students seeking help with projects. However, whilst statistics support tutors cannot be expected to understand the research context within all academic disciplines or help formulate research questions, it was agreed that sometimes asking probing questions of the student about what they hoped to learn from their study and/or the nature of the data they have or plan to collect could help the student clarify their aims. If after a session focused on these aspects, the student still wasn't sure of their aims or were unable to formulate a hypotheses or research questions, it was recommended that they are re-directed back to the supervisor.

In contrast, other aspects of support with student projects, such advising on study design, data collection and project management, it was felt could be considered as falling within the remit of statistics support. However, it was agreed that students' project supervisors should play a key with some of these aspects, particularly when there is a context of the project that related to supervisors' specialist areas. Another issue that was raised related to supporting Postgraduate Taught (PGT) students, where the demand for help peaks in the summer when many PGT students' supervisors take annual leave. In these circumstances it is not uncommon for the student to perceive the statistics tutor as a surrogate supervisor for their project, and so the statistics tutor should take care to explain their role and manage the student's expectations. It was reported that Chester University have 
trialled a scheme where statistics support tutors attend initial dissertation meetings with students with the student's supervisors present to offer guidance at the beginning. Whilst providing this sort of support/training for supervisors would clearly be beneficial in the long run, discussion centred on whether this was feasible in larger institutions. It was suggested that advising groups of project supervisors on study design and analysis, in a workshop context, could work but whether this should be within the remit of statistics support was questioned as well as whether it was manageable in larger institutions.

\subsection{Supporting students with choosing statistical techniques}

There were many issues raised relating to the expectations of students and project supervisors. These included students seeking help with techniques suggested by their supervisor or teacher that appear to be inappropriate, choosing the appropriate level of statistics to support a project student with and whether this choice conflicts with the suggestions from the student's supervisor.

Many students come to statistics support with an idea of the technique they want help with, or may have been suggested by their supervisor or teacher, but often the suggested technique is considered by the statistics support tutor to be inappropriate or perhaps too advanced for the student given their evident mathematical/statistical expertise or the time frame within which the student is working. A student obviously wants to do as their supervisor suggests, even if they have no idea what the technique is or why it is appropriate. It was agreed that it is important to check why the student or their supervisor thinks they should use a specific technique and how it relates to their research questions. In addition it is equally important for the statistics tutor to explain to the student (and their project supervisor) the justification for any suggestions the tutor makes for using a different technique to the one the student or their supervisor had suggested.

If a student's project supervisor has suggested inappropriate methods, the statistics support tutor should be cautious, since ultimately it is the supervisor who will assess the student's work. In addition, good close relationships between statistics support staff and the staff teaching students is are vital, to maintain the support of teaching staff in promoting the value of using mathematics and statistics support centres.

The general consensus was that the statistics support tutor talks through the research questions and possibilities for analysis with the student and suggests that the student then talks through the options with their supervisor. This also applies to techniques which the statistics support tutor feels are too advanced for the student given the students level of ability or time frame. Students often worry if using simpler techniques will reduce their grade, therefore it is important to stress that understanding and reporting the chosen technique in relation to the research question is preferable to doing more complex analysis badly or incorrectly. It was also agreed that the importance of ascertaining the student's prior statistical knowledge, clarifying expectations and the time available, before making any suggestions regarding techniques, are all elements of good practice in providing statistics support. If a student is new to statistics and has more time, basic hypothesis testing using a simple test should be discussed first before moving up to more complex analyses.

Statistics teaching in general typically follows a "cookbook" focusing on individual techniques one at a time, with little or often no attention paid to when or why any specific technique would be relevant. As a result it was agreed that most students struggle when choosing the most appropriate methods of data collection and analysis for their data. This is compounded by the fact that when project students first seek statistics support, they have often already collected their data, often using a poor study design. Choosing the correct technique is an integral part of a statistics support session, which should be carried out even if the student thinks they know the appropriate analysis. It was agreed that helping students understand which technique is suitable can be achieved using flow charts or tables based on the data types of their independent/dependent variables rather than just informing 
them with no explanations. Some useful resources that were discussed include those available through the Sheffield Hallam Maths and Stats support centre website at https://maths.shu.ac.uk/mathshelp/Resources/testchoose.html, or the whattest resource available from the Mathematics Learning Centre at Loughborough University via http://whattest.lboro.ac.uk/index.html

Given the number of students requiring help with the process of choosing the right technique, embedding these skills within taught modules would clearly be the most beneficial approach. However, it was evident that some mathematics and statistics support centres also run workshops on this aspect of statistics.

Finally, in relation to supporting students with the right technique, it should be acknowledged that there will be, and often are, limitations on the range of statistical techniques that staff within a mathematics and statistics support centre have expertise in, particularly where statistics support is offered by non-specialists. As with providing support with a range of statistical software discussed in the previous section, it was agreed that it should be possible to give an overview of the level of statistics taught within individual centres, via centre websites etc. As a closing remark in this section, in the case of less well known statistical techniques, one suggestion was to ask the lecturer who specified the technique to teach support staff about the topic.

\subsection{Advertising and evidencing the impact of statistics support}

There are many modes of advertising used by mathematics and statistics support centres to raise awareness amongst the student population that statistics support is available. Although advertising during induction/welcome weeks, through events, talks and emails is common, it was agreed that this was not the best time to advertise statistics support, as students were often overloaded with information at that time, and more importantly their awareness of the need for statistics support would not yet be evident. Word of mouth was generally seen as an effective method of advertising and increasing awareness through lecturers, students union and student ambassadors for more timely advertising helped with this. In particular, it was felt that developing relationships with staff that lead project modules across the institution would be beneficial to facilitate timely promotion of the availability of statistics support and the need to seek advice on study design and data collection early. Having a good website presence which is easy for students to find and networking at higher levels to spread the word about the service was also suggested.

Discussion also took place about evaluating the impact of mathematics and statistics support, in order to raise the profile and demonstrate the value of the service to both students and the institution. It was agreed that surveying students who had used statistics support, particularly around the impact of the help they received in reducing their perceived risk failing or dropping out, would offer some evidence to support the development or continuation of statistics support provision in an institution. Finally it was agreed that networking with relevant committees and management across the institution, would also help in terms of promoting evidence of the impact that statistics support provision has on reducing student attrition, as well as contributing to positively to outcomes related to the NSS (and ultimately the TEF).

\section{Summary}

The Special Interest Group (SIG) in Statistics Support, maintained by the sigma Network for excellence in mathematics and statistics support, held a very valuable workshop at the CETL-MSOR conference 2018. This was focused on identifying and addressing issues within statistics support and facilitated a very interesting and valuable sharing of experiences and suggestions for good practice in the provision of statistics support. Discussions were primarily focused on the limitations and scope of statistics support, although some additional issues were a focus for discussion. Specific 
topics that were discussed included supporting student with statistics software, understanding the remit of statistics support, supporting students with choosing statistical techniques, as well as a short discussion on raising awareness of statistics support and evidencing its impact. One key action arising from the workshop was the proposal to run a workshop on statistics software.

\section{Appendix}

Written comments recorded at the workshop: Group 1

\begin{tabular}{|c|c|}
\hline $\begin{array}{l}\text { Batance between levet } \\
\text { Anxiety of non significant result c } \\
\text { techiques which are too basic } \\
\text { Using different terminology } \\
\text { What do you want to do - choose } \\
\text { Research shesis } \\
\text { Minimising no. of questions }\end{array}$ & $\begin{array}{l}\text { Advertising t data collectic } \\
\text { - Statements about dropping o } \\
\text { - Student evaluation } \\
\text { - Survey students for opin } \\
\text { on usetuliess } \\
\text { - TEf goots gold - student sa } \\
\text { - Academic consel network } \\
\text { - Speak to lecturer discaveren, } \\
\text { + student wion + ambassoders }\end{array}$ \\
\hline
\end{tabular}


Written comments recorded at the workshop: Group 2
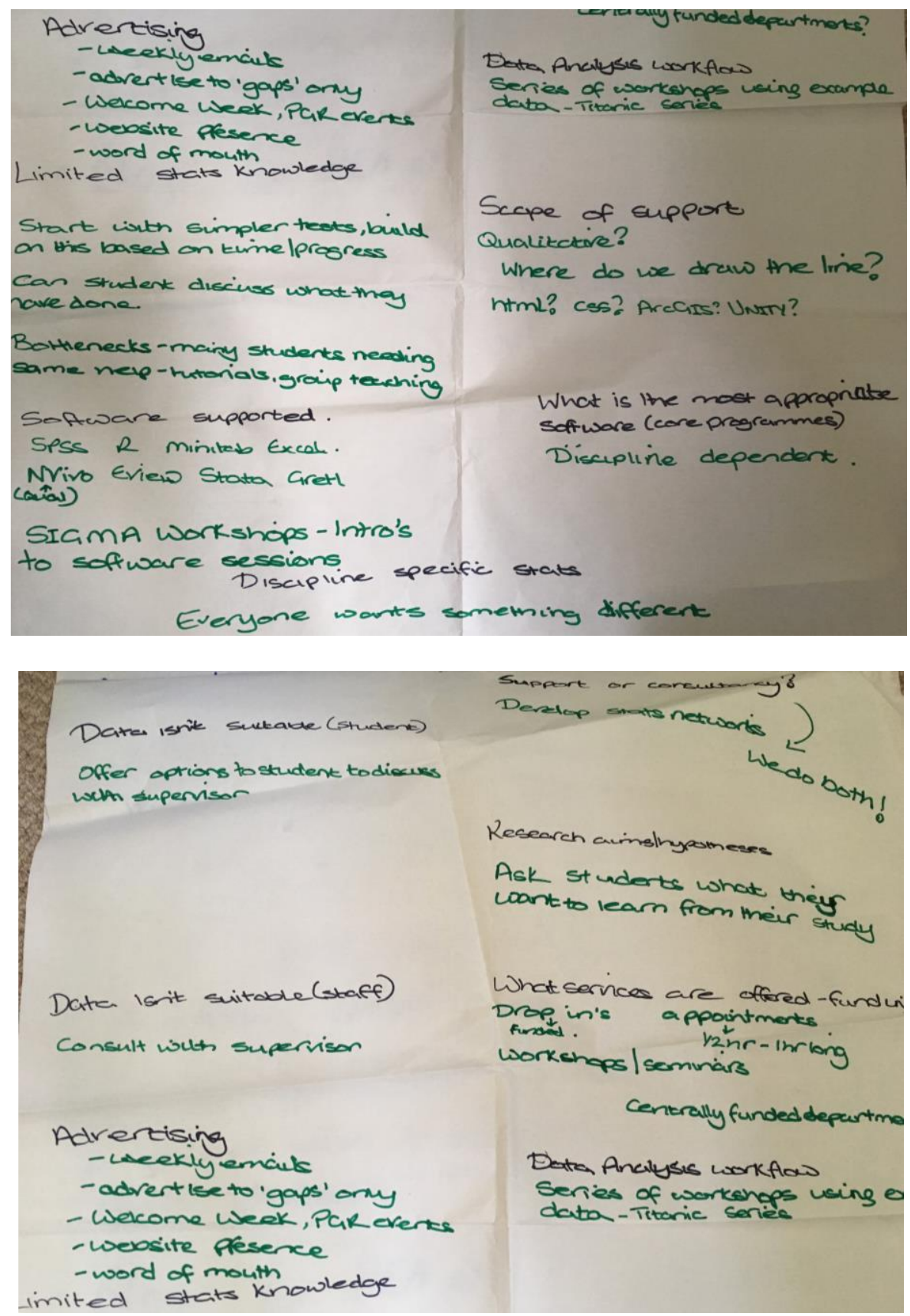

\section{Acknowledgements}

The authors would like to thank and acknowledge all of those colleagues that contributed to the padlet postings prior to the conference and those that took part in the workshop. These include Alison Loddick, Carole Davenport, Cath P, Chetna Patel, Éva Szatmari, Jia Shao, Liam Brierley, Monica-Christina Hess, Morag McFadyen, Nick Goddard, Paul Rice, Peter Mitchell and Shirley J. Without their contributions the workshop and this report, and the subsequent sharing of good practice would not be possible. Our apologies to anyone we have forgotten to include. 